\title{
Mycobacterium peregrinum
}

National Cancer Institute

\section{Source}

National Cancer Institute. Mycobacterium peregrinum. NCI Thesaurus. Code C86546.

A species of aerobic, Gram positive, rod shaped bacterium assigned to the phylum Actinobacteria. This species is acid fast, grows rapidly on egg medium, is urease, arylsulfatase and nitrate reductase positive, benzamidase and isonicotinamidase negative, and has a relatively low tolerance to cefmetazole and cefoxitin. M. peregrinum is found in soil and water-related sources and is related to surgical site and catheter related infections. 